\title{
The Race Against Time to Save the Planet for Future Generations
}

\author{
Ahmad Badri Abdullah*
}

While we are still dealing with the COVID-19 pandemic, the impact of planetary catastrophes has begun to rear its ugly head. Spain, Greece and China are suffering from heat waves, high temperatures, extreme flooding, and deadly wildfires. In an interview on the Veritasium channel, Bill Gates stated that climate change and bioterrorism will be the next challenges to strike humanity post-pandemic.

This is made clear by the alarming code red warning issued by the United Nations Intergovernmental Panel on Climate Change, in their report 'Climate Change 2021: The Physical Science Basis,' which estimates the world will warm by more than $1.5^{\circ} \mathrm{C}$ over the next decade.

Climate-related hazards, such as health and livelihood issues, food scarcity, a lack of clean water, security and economic threats, are expected to intensify if global warming exceeds $2^{\circ} \mathrm{C}$. Unfortunately, it has been found that in Malaysia, public awareness of climate change is persistently poor, ranging from 32 to 40 per cent of the population.

Despite the fact that Malaysia has experienced extreme weather and flooding on a yearly basis, Malaysians are unable to link these disasters to climate change. Malaysia lags behind Indonesia, Vietnam, and the Philippines in the adoption of renewable energy in the energy industry, manufacturing, and transportation these other countries have high rates of adoption approaching 30 per cent.

In fact, Malaysia's largest carbon emitters are the energy, transport, manufacturing, agricultural, and waste management industries. Therefore, it takes unwavering political will among the country's leadership to reach the necessary pace and scale of change. The IPCC has proposed that the world reach zero carbon emissions by 2050 , while Malaysia has pledged to reduce its greenhouse gas emission intensity of gross domestic product by up to 45 per cent by 2030 .

Government intervention in realising green targets, appropriate policy implementation, and active monitoring of green company performance is crucial. More importantly, the country must consider its long-standing approach to natural resources-led development over environmental protection, and shift toward ecologically sustainable growth. 
A two-pronged strategy needs to be adopted. First, current efforts should be accelerated. Second, a new circular economic concept and practice-oriented culture should be developed. The ministries in charge of the environment, water, energy, natural resources, agriculture, plantations, and commodities must play a strategic role in reducing carbon emissions. Moreover, the government and the public must guarantee that long-term plans, such as the Green Technology Master Plan 2017-2030 and Malaysia's Roadmap Towards Zero Single-Use Plastics 2018-2030, are implemented effectively. In 2015, the government made it mandatory for households to segregate solid waste at the source, with the Ministry of Housing and Local Government enforcing the Solid Waste and Public Cleansing Management Act 2007 (Act 672).

However, the lack of a unified solid waste management strategy has resulted in a waste recovery rate of less than five per cent. Therefore, developing a clear waste management policy is critical, especially in major cities. Cities like San Francisco and Seoul should serve as models. Thanks to effective policies and laws, these locations have been able to remove 80 per cent of their local daily waste from landfill by recycling and converting food wastes into compost for plantations.

Malaysian authorities must aggressively implement policies that improve the lifestyle of its population, in addition to a circular economic strategy and regulations for manufacturing and waste management. This primarily involves redesigning business models such that all products manufactured are easily recycled, repurposed or reused, and employ sustainable raw materials. This may guarantee that products last as long as possible, while minimising the use of natural resources in the creation of new ones.

The formation of a Special Parliamentarian Committee on Environment, Climate Change, Energy and Technology, as announced by the Parliament speaker in 2019, is more important than ever. This committee must serve as a coordinator for multidimensional strategies to mitigate the impact of climate change. If we are serious about preserving the planet for future generations, we should not waste time in pulling together across sectors and organisations.

\section{Notes}

* Ahmad Badri Abdullah is a Research Fellow and currently Head of Science, Technology, Environment and Ethics Unit at the International Institute of Advanced Islamic Studies (IAIS) Malaysia. He can be contacted at: badri@, iais.org.my. 